\title{
Intervenções comunitárias em enfermagem: intersetorialidade, formação empreendedora $e$ desenvolvimento regional em saúde
}

\author{
Gímerson Erick Ferreira \\ Universidade Federal do Mato Grosso \\ Edemilson Pichek dos Santos \\ Faculdades Integradas de Taquara \\ Amanda Silveira Duarte Gomes \\ Faculdades Integradas de Taquara \\ Claudia Capellari \\ Faculdades Integradas de Taquara \\ Roberto Tadeu Ramos Morais \\ Faculdades Integradas de Taquara
}

\begin{abstract}
Resumo
Compreendendo desenvolvimento regional para além de seu caráter econômico, mas envolvendo qualidade de vida da população e participação cidadã, entende-se a saúde como importante determinante desse processo. Neste artigo, pretendeu-se analisar as contribuições das intervenções comunitárias com enfoque na educação para a saúde, mobilizadas por acadêmicos de enfermagem de uma Instituição de Ensino Superior - IES do Vale do Paranhana/RS. Estudo do tipo qualitativo e exploratório, amparou-se em uma pesquisa documental aos relatórios de intervenções da IES, cujos dados foram analisados de forma interpretativa. Diante dos dados coletados, percebeu-se que as instituições de educação básica não estiveram presentes em nenhuma ação, apesar de existir um programa governamental específico que estreita a relação entre educação e saúde. Esse é um ponto importante a ser trabalhado em ações futuras, dado o potencial de inserção e mobilização comunitária que essas instituições têm. Pôde-se concluir que ações comunitárias em saúde têm grande potencial de mobilizar diversos atores e setores, contribuindo para a cooperatividade, além de proporcionarem aos acadêmicos uma formação mais próxima da realidade regional.
\end{abstract}

Palavras-chave: Ações comunitárias em saúde. Enfermagem. Desenvolvimento Regional. 
Intervenções comunitárias em enfermagem: intersetorialidade, formação empreendedora e desenvolvimento regional em saúde

\title{
Community interventions in nursing: intersectoriality, entrepreneurship training and regional health development
}

\begin{abstract}
Making use of the concept of regional development beside of his economic character but including quality of life of the population and the citizen participation, the health is understood has decisive in this process. In this papper it is intended analyze the contributions of the community interventions with objective in education for health, making by academics of nursing from higher education institution (HEI), sited in Paranhana's Valley/RS. This qualitative and exploratory study, has been supported in a documental research to interventions reports from $\mathrm{HEl}$, whose data was analyzed of interpretative way. In the face of the collected data, was perceived that elementary, middle and high school institutions did not participated of the actions, although there is a governmental program that close relation between education and health. This is a important point to be worked in future actions, because these institutions have potential to be inserted and to mobilize the community. It could be concluded that community actions in health have a important potential to mobilize many actors and sectors, to contribute to the cooperatively, besides to offer to academics a formation more near of regional reality.

Key words: Community actions in health. Nursing. Regional development.

\section{Intervenciones comunitarias en enfermería: intersectorialidad, formación emprendedora y desarrollo regional en salud}

\begin{abstract}
Resumen
Partiendo de lo desarollo regional para allá de su carácter económico, pero abarcando calidad de vida de la población y participación ciudadana, se entende la salud como important determinante factor de ese proceso. En este artículo científico se ha pretendido analizar las contribuciones de las intervenciones comunitarias con enfoque en la educación para la salud, que se han movilizado por medio de alumnos de pregrado en enfermería, de una institución de enseñanza superior (IES) localizada en el Vale de lo Paranhana/RS. El estudio calitativo y exploratorio, ha se amparado en una investigación documental a los informes de intervenciones de la IES, cuyas informaciones han sido analizadas de manera interpretativa. Delante de los datos recogidos, se ha notado que las instituciones de enseñanza fundamental y media no participaron de ninguna acción, aunque exista un programa gubernamental definido que hace estrecha la relación entre educación y salud. Ese es un punto importante a ser desarrollado en acciones futuras, haya vista lo potencial de inserción y movilización comunitaria que esas instituciones poseen. Se puede concluir que acciones comunitarias en salud tienen un gran potencial para movilizar diversos actores y sectores, contribuyendo para la cooperación, allá de proporcionar a los universitarios una formación más cercana a la realidad de la región.
\end{abstract}

Palabras clave: Acciones relacionadas con la salud. Enfermería. Desarrollo Regional.

\section{INTRODUÇÃO}

O setor da saúde tem se destacado como elemento fundamental para o desenvolvimento regional. Sua importância é crescentemente reconhecida em diversos estudos que demonstram a clara necessidade de integração entre saúde e desenvolvimento, ao analisar os fatores determinantes das condições de vida, saúde e bem-estar (GADELHA; COSTA, 2012). Fischborn (2015) assevera que, ao se 
pensar em desenvolvimento, para além dos aspectos econômicos, é necessário considerar o acesso aos serviços de saúde e educação, e as condições de moradia e de trabalho, ao que Dreher e Ullrich (2010) complementam, afirmando que o desenvolvimento está diretamente relacionado à autoconfiança coletiva e ao agir de forma cooperativa na invenção e reinvenção de recursos do próprio território, adquirindo, assim, um caráter comunitário.

Entre as condições de saúde da população e sua capacidade de desenvolvimento econômico está o reconhecimento do papel central da saúde nas concepções de desenvolvimento, inclusive na sua dimensão territorial. Se, por um lado, a saúde constitui-se essencialmente como fator de integração entre a sociedade e seus cidadãos, por outro, necessita de artifícios de integração entre seus atores sociais (GADELHA; COSTA, 2012). Nesse contexto, aponta-se para o papel desses sujeitos e das organizações regionais para o protagonismo na construção de ações de desenvolvimento sustentável e de práticas de valorização da vida (SEBASTIANY, 2012).

Há de se considerar que tais agentes se encontram imersos no cenário resultante do processo de globalização, no qual as discrepâncias entre as condições e o acesso à saúde, resultantes especialmente da economia de mercado, marcam a realidade dos brasileiros. Na busca da superação das desigualdades sociais, fortalecer as regiões a partir do empoderamento dos atores sociais para a busca de soluções constitui ferramenta potente para o enfrentamento dos problemas (SEBASTIANY, 2012).

No cenário brasileiro, o Estado representa papel central, como responsável pela promoção da saúde, a partir da elaboração, implementação e controle de políticas públicas que garantam o acesso universal aos serviços de saúde, contando com a participação popular (BRASIL, 1988). Dessa forma, tem-se o Sistema Único de Saúde - SUS como uma importante política pública descentralizadora, que apontou para novos modos de pensar e de produzir saúde, a partir da orientação de seus princípios doutrinários (OLIVEIRA; LIMA, 2003). Estes remetem à consolidação do conceito ampliado de saúde e fortalecem o direito à saúde, mediante alguns princípios, entre eles: universalidade (acesso aos serviços de saúde, conforme as necessidades de saúde do indivíduo); equidade (atendimento às necessidades de saúde de acordo com as prioridades de cada indivíduo, família, grupo ou população), considerando que no Brasil estas necessidades variam, em razão das inúmeras disparidades sociais, econômicas, políticas e regionais; integralidade (ao considerar as necessidades de saúde, para além da sua queixa ou doença, e, portanto, considerando os aspectos biopsicossociais das pessoas ou dos grupos) (CALDAS; SANTOS, 2016).

Dentre as iniciativas para a consolidação do SUS, destaca-se a Política Nacional de Promoção da Saúde, que instituiu uma agenda de ações com vistas à saúde preventiva, em que destaca a necessidade de considerar a participação comunitária e intersetorial, respeitando-se as identidades regionais (BRASIL, 2010). A articulação entre as ações de promoção da saúde e da educação constituem estratégias essenciais ao alcance de melhores resultados nas práticas de atenção à saúde.

Na seara da enfermagem, tais estratégias ganham destaque, pois, em geral, suas ações partem de um olhar diagnóstico para as necessidades da população, 
Intervenções comunitárias em enfermagem: intersetorialidade, formação empreendedora e desenvolvimento regional em saúde

com vistas ao levantamento de possibilidades de intervenções em saúde, permitindo que estas façam mais sentido para os sujeitos. Essa perspectiva favorece ao sujeito perceber-se como agente de transformação em uma relação dinâmica com outros agentes e situações, em alinhamento aos princípios do SUS (NASCIMENTO; FERNANDES, 2008; PINHEIRO; GUANAES, 2011).

Além disso, remete à especificidade e ao protagonismo da enfermagem nessa construção intersetorial, uma vez que esta assume o processo de cuidado como centralidade do seu fazer. Cuidado este compreendido como processo, por enfocar a dinâmica que circunda as boas práticas de saúde e não simplesmente a cura da doença. Essa perspectiva demanda olhar acurado para as necessidades e subjetividades de indivíduos, famílias e comunidades, bem como a articulação de saberes interdisciplinares, envolvendo os diversos atores e cenários estratégicos que têm interface com o processo de cuidado.

Assim, a enfermagem, tendo o cuidado como centralidade, manifesta potência para transitar em diferentes campos sociais, estabelecendo canais de interlocução com agentes da saúde e de outros setores, com vistas ao desenvolvimento de ações comunitárias em saúde, necessárias às boas práticas e no processo de cuidado a indivíduos, famílias, grupos e comunidades. Tais ações possibilitam intervir proativamente em determinado cenário, favorecendo a transformação de realidades e contribuindo com o desenvolvimento regional em saúde, sendo fundamental que estas sejam estimuladas ainda no âmbito da formação.

Entretanto, percebe-se que a maioria das análises de iniciativas de desenvolvimento regional em saúde centram-se, principalmente, em realidades de longa data, sendo fundamental conferir visibilidade também a ações comunitárias pontuais e que propiciam a intersetorialidade, a formação empreendedora e o desenvolvimento regional. Do mesmo modo, nota-se que as intervenções realizadas no âmbito da formação em enfermagem, tradicionalmente norteiam-se por ações clínico-assistenciais, desconsiderando a necessidade de investir em estratégias que promovam o desenvolvimento de intervenções comunitárias, pensadas a partir da realidade local e de modo compartilhado entre os diversos atores sociais.

Face ao problema exposto, indagou-se: que intervenções comunitárias, no âmbito das práticas de cuidados de enfermagem, podem favorecer a intersetorialidade, a formação empreendedora e o desenvolvimento regional em saúde? Considerando a necessidade de contribuir com a produção de conhecimento sobre questões que envolvem as iniciativas comunitárias em apoio ao desenvolvimento regional em saúde, construiu-se este artigo com o objetivo de analisar as intervenções comunitárias empreendidas no âmbito da formação em enfermagem e que podem favorecer o desenvolvimento regional em saúde.

\section{METODOLOGIA}

Estudo de abordagem qualitativa do tipo exploratório-descritiva, realizado mediante análise documental. A análise documental em pesquisa é um procedimento que engloba identificação, verificação e apreciação de documentos que mantêm relação com o objeto investigado (POUPART, 2014). Neste estudo, a análise deu-se mediante apreciação de documentos e registros de atividades 
comunitárias desenvolvidas no âmbito da disciplina de Estágio Curricular Supervisionado - ECS, realizado em serviços da Atenção Primária à Saúde - APS, do Curso de Enfermagem - Bacharelado, de uma IES, de caráter comunitário, situada no Vale do Paranhana/RS.

A região do Vale do Paranhana é composta por seis municípios, sendo eles: Igrejinha, Parobé, Riozinho, Rolante, Taquara e Três Coroas, e registrava, em 2014, uma população de 196.158 habitantes, totalizando uma área de aproximadamente $1.424,7 \mathrm{~km}^{2}$ (FEE, 2015). O setor econômico de maior importância na região é o industrial, mais precisamente o calçadista, seguido pelo setor agropecuário e pela produção de hortifrutigranjeiros (BASSAN, 2017). Em 2012, a média do Índice de Desenvolvimento Socioeconômico - IDESE na região era de 0,701 , um pouco abaixo da média estadual de 0,744 (RIO GRANDE DO SUL, 2015). Essa condição reflete no cenário de desenvolvimento do setor saúde, o qual, no âmbito da Atenção Primária à Saúde, dispõe de 38 Unidades Básicas de Saúde - UBS, oito Estratégias de Saúde da Família - ESF, seis Centros de Atenção Psicossocial - CAPS, além das Secretarias Municipais de Saúde - SMS de cada município. No município em que se situa a IES, palco deste estudo, e no qual são desenvolvidas majoritariamente as atividades acadêmicas desta, conta-se hoje com uma SMS, à qual vinculam-se nove UBS, duas ESF e dois CAPS (BRASIL, 2018).

O ECS neste Curso é desenvolvido em 400 horas, durante o penúltimo semestre letivo da formação como enfermeiro, e requer, para o alcance das competências formativas, atividades clínico-assistenciais, gerenciais, investigativas, educativas e de participação política. Dentre estas, os alunos são instigados a pensar, criar e empreender, com base em análise situacional da região, ações de enfermagem e saúde capazes de intervir em um cenário local que requeira o desenvolvimento de práticas de prevenção e promoção da saúde. Como estes cenários variam, em decorrência da análise situacional realizada, e em consenso entre os acadêmicos, docentes supervisores, enfermeiros preceptores, as atividades foram denominadas de Atividades Itinerantes na Atenção Básica - AIAB.

Para o desenvolvimento das AIAB, os acadêmicos são encorajados, após definirem o cenário de implementação, a envolverem-se com os diversos atores sociais da comunidade local, compartilhando opiniões, saberes e decisões acerca do que pretendem desenvolver, e angariando recursos diversos, com vistas à implementação de ações que atendam às necessidades de saúde locais. Para tanto, o grupo de acadêmicos desenvolve um Plano de Intervenção Comunitária, em que precisa estruturar, de modo compartilhado, todo o seu percurso na AIAB e de todos os recursos e práticas a serem desenvolvidas. No Plano, constam as metas almejadas para a AIAB, e informações de apoio que irão fornecer subsídios para a intervenção desenvolvida.

Ao final, estes precisam apresentar o Plano de Intervenção Comunitária de modo simplificado, em que conseguem exercitar sua tarefa final, ao verbalizar com seus orientadores, em um processo de feedback, a descrição, análise e reflexão de todo o seu percurso no desenvolvimento da AIAB, e de todas as ações e intervenções empreendidas. Ao apresentarem o Plano Simplificado, os alunos são encorajados a relatar o modo como aprenderam fazendo, considerando os desafios encontrados para que conseguissem atingir a meta anteriormente proposta, bem 
Intervenções comunitárias em enfermagem: intersetorialidade, formação empreendedora e desenvolvimento regional em saúde

como os erros e lições nesta execução, assumindo-as como fonte de aprendizado, em um movimento de avaliação do conhecimento produzido.

A coleta de dados deu-se em análise aos documentos e registros que remetem às AIAB desenvolvidas no período de março de 2016 a novembro de 2017. Os dados obtidos nesses documentos e registros foram selecionados e organizados em uma planilha no Microsoft Excel ${ }^{\circledR}$, com vistas a traçar um panorama das ações e intervenções comunitárias empreendidas. Considerou-se para a apresentação desse panorama os seguintes critérios: título da intervenção realizada; objetivo da intervenção; parcerias realizadas; ações desenvolvidas; público alvo e número de população atendida. Após a estruturação, realizou-se a análise dos dados, interpretação, síntese e discussão dos resultados, emergindo os resultados dos possíveis impactos gerados a partir das intervenções empreendidas, bem como as contribuições que estes podem gerar para o desenvolvimento regional em saúde na região do Vale do Paranhana.

\section{RESULTADOS E DISCUSSÕES}

A análise às intervenções comunitárias mapeadas revelou que elas atuam como gatilhos disparadores do desenvolvimento regional em saúde. A partir do objetivo deste artigo, e de posse do mapeamento das atividades itinerantes realizadas, teceu-se um paralelo entre as contribuições das intervenções comunitárias de enfermagem, na perspectiva de ações em saúde no contexto de desenvolvimento regional, das quais emergiram as categorias temáticas apresentadas e discutidas a seguir.

\section{Integração ensino-serviço-comunidade visando boas práticas comunitárias}

A aproximação das IES com a sociedade tem recebido destaque no cenário contemporâneo, visto que ela se faz necessária para compreender as reais necessidades da população. Com isso, origina-se uma nova visão paradigmática que enfatiza a prestação de cuidados focados na promoção da saúde, articulada com contextos sociais e ambientais. Para Quezada (2011), o ensino universitário em todo o mundo tem sido visto sob a necessidade de evoluir ao passo das mudanças que acontecem no sistema educacional e no mercado de trabalho, para atender às novas demandas na formação de profissionais, imersas na crescente globalização de atividades humanizadas.

Nesse contexto, encontra-se a IES e o curso de Enfermagem de que trata este artigo. A IES, de caráter comunitário, traz o desenvolvimento regional como um de seus pilares, impulsionado por seu compromisso social, em buscar transformações por meio da gestão e difusão do conhecimento, por sua missão, promovendo a formação integral do ser humano, e por seus princípios institucionais, dentre os quais se destacam o empreendedorismo e a regionalização (FACCAT, 2017). Imerso nessa conjuntura, o Curso de Enfermagem tem a humanização do cuidado como um princípio transversal, atrelado ao compromisso com a formação de profissionais cidadãos. Nesse sentido, responde ao compromisso da universidade com o desenvolvimento regional, com a cidadania e ética, com a inclusão social, com a saúde e bem-estar e com a educação ao propor 
atividades que aproximam os estudantes do contexto regional e dos cenários de cuidado que exigem postura proativa e resolutiva.

A realização das atividades comunitárias, num contexto social aquém de conhecimentos básicos de cuidado com a saúde, desperta a sensibilidade nos acadêmicos para a busca de conhecimentos e para a elaboração de maneiras de reproduzi-lo, de maneira significativa. Ao aproximar o acadêmico de tais cenários sociais e mobilizá-lo para o encontro com a comunidade, torna-se o processo de aprendizagem dotado de significados ao promover respostas a demandas encontradas. Assim, essa aproximação é potencialmente indutora do desenvolvimento dos sujeitos implicados e, consequentemente, da região em que estão inseridos. Trabalhos realizados por cursos da área da saúde têm utilizado a problematização da realidade (BRANDÃO; ROCHA; SILVA, 2013) e a imersão nos cenários comunitários (PIZZINATO et al., 2010) para promover o aprendizado.

Em pesquisas que fazem referência aos cursos envolvidos na integração ensino e serviço, os cursos de Enfermagem têm recebido destaque (KUABARA et al., 2014). Entretanto, são ponderadas as particularidades de cada IES no envolvimento de integração ensino e serviço, o que pode indicar a desarticulação entre os cursos da área da saúde, uma vez que a maioria das instituições de ensino conta com suas singularidades no método de ensino. Nesse sentido, através deste trabalho, é notável a participação dos acadêmicos no processo de integração ensino-serviço-comunidade, demonstrando o seu envolvimento com as boas práticas comunitárias, essenciais ao processo de cuidado, tornando-os protagonistas do seu processo de formação mediante essa articulação.

As atividades aqui relatadas, conforme constam no Quadro 1, além de significar e imergir os acadêmicos em espaços da comunidade, diferenciam-se por serem propulsoras de movimento que envolve os atores do espaço em que é realizada a ação, tornando-os sujeitos dela. Ao considerarem as características e necessidades diagnosticadas em cada cenário, e promovendo a integração dos atores estratégicos que atuam na comunidade, reavivam o saber oriundo das teorias e práticas adquiridos na universidade, entrelaçando-o com o saber popular.

Nesse sentido, os acadêmicos encontram sentido para as ações que visam desenvolver, pois são provocados a segmentar o contexto de sua intervenção, identificando as necessidades de saúde de indivíduos, grupos e comunidades, e a conceber práticas de cuidado que favoreçam a prevenção e a promoção da saúde. Esse movimento de pensar-refletir-agir desperta 0 acadêmico para 0 desenvolvimento e implementação de ações transformadoras da realidade em que se encontram, contribuindo para o desenvolvimento regional em saúde.

No Quadro apresentado, observa-se a colaboração de diferentes setores da sociedade, situados em diferentes municípios do Vale do Paranhana - RS. Convergindo mais estreitamente com a própria prática da enfermagem estão os CAPS, as SMS, e as ESFs. Também contribuíram com as intervenções, organizações e serviços vinculados à assistência social, a exemplo de Centros de Referência de Assistência Social - CRAS e Organizações Não Governamentais - ONGs, além de organizações diversas da sociedade civil, por meio da Associação de Automobilísticos e do Serviço Social da Indústria - SESI. 
Intervenções comunitárias em enfermagem: intersetorialidade, formação empreendedora e desenvolvimento regional em saúde

\section{Quadro 1. Descrição das intervenções comunitárias realizadas no âmbito da APS, por acadêmicos de Enfermagem - Bacharelado do ECS, Vale do Paranhana, RS, \\ Brasil, 2018}

\begin{tabular}{|c|c|c|c|}
\hline ANO & AIAB & OBJETIVOS E METAS & PARCERIAS \\
\hline 2016 & $\begin{array}{l}\text { - Dia da Saúde e Bem- } \\
\text { Estar } \\
\text { - Primeiros Socorros } \\
\text { - Saúde em Foco } \\
\text { - Só para elas: saúde e } \\
\text { bem-estar } \\
\text { - Setembro Amarelo } \\
\text { - Primeiros Socorros } \\
\text { na Infância } \\
\text { - Mulheres em Ação } \\
\text { - Ação Novembro } \\
\text { Azul. }\end{array}$ & $\begin{array}{l}\text { - Incentivar a organização, planejamento, } \\
\text { articulação política e coordenação de eventos } \\
\text { comunitários pelos estagiários de } \\
\text { enfermagem; } \\
\text { - Possibilitar o fortalecimento do vínculo entre a } \\
\text { comunidade o os serviços de saúde prestados, } \\
\text { visando aproximar a comunidade do serviço e } \\
\text { fortalecer o vínculo com as pessoas } \\
\text { - Desenvolver ações de educação e promoção } \\
\text { da saúde na comunidade; } \\
\text { - Oferecer à população educação em saúde e } \\
\text { promoção da saúde: orientação sobre } \\
\text { Doenças Crônicas Não-Transmissíveis; } \\
\text { - Desenvolver ações de promoção e prevenção } \\
\text { de saúde para a comunidade. } \\
\text { - Fornecer orientações sobre o movimento } \\
\text { Outubro Rosa e Novembro Azul, com vistas à } \\
\text { prevenção e combate ao câncer de mama, } \\
\text { colo de útero e próstata. }\end{array}$ & $\begin{array}{l}\text { - CAPS* } \\
\text { - CRAS } \\
\text { - ESF } \\
\text { - ONG } \\
\text { - SESI******* } \\
\text { - SMS } \\
\text { - SM***** }\end{array}$ \\
\hline 2017 & $\begin{array}{l}\text { - Enfermagem, Cuidado } \\
\text { e Cidadania } \\
\text { - Saúde no Morro } \\
\text { - Circuito da Saúde } \\
\text { - Arraiá da Saúde } \\
\text { - Volta por Cima } \\
\text { - Outubro Rosa e }{ }^{1} \\
\text { Corrida Rosa } \\
\text { - Novembro Azul }\end{array}$ & $\begin{array}{l}\text { - Oferecer à população educação em saúde e } \\
\text { promoção da saúde: orientação sobre as } \\
\text { Doenças Crônicas Não-Transmissíveis. } \\
\text { - Fornecer orientaçães sobre direitos sociais, } \\
\text { promoção e prevenção de saúde para a } \\
\text { comunidade. } \\
\text { - Demonstrar formas de coleta segura de } \\
\text { resíduos contaminados. } \\
\text { - Incentivar práticas de desenvolvimento de } \\
\text { exercícios físicos. } \\
\text { - Oferecer à comunidade momentos de } \\
\text { acolhimento e promoção da saúde. } \\
\text { - Identificar e orientar acerca de fatores de risco } \\
\text { cardiovascular, orientação sexual, higiene } \\
\text { bucal e atividades lúdicas com crianças. } \\
\text { - Incentivar a utilização de espaços públicos e } \\
\text { desenvolvimento de atividades para o bem- } \\
\text { estar mental. } \\
\text { - Divulgar o movimento Outubro Rosa, com } \\
\text { vistas à prevenção e combate ao câncer de } \\
\text { mama, por meio de "Corrida Rosa". } \\
\text { - Oferecer à comunidade orientações de } \\
\text { prevenção e promoção à saúde por meio de } \\
\text { ações de educação e lazer, com foco na saúde } \\
\text { do homem. }\end{array}$ & $\begin{array}{l}\text { - Associação de } \\
\text { automobilismo } \\
\text { - } \text { CAPS }^{*} \\
\text { - } \text { CRAS }^{* *} \\
\text { - ESFs } \\
\text { diferentes } \\
\text { municípios } \\
\text { - ONGs } \\
\text { - Quiropraxistas } \\
\text { - SESI } \\
\text { - SMS } \\
\text { di*******ntes } \\
\text { municípios }\end{array}$ \\
\hline
\end{tabular}

Fonte: quadro elaborado pelos autores, 2018. *CAPS - Centro de Atendimento Psicossocial; **CRAS Centro de Referência de Assistência Social; ***ESF - Estratégia de Saúde da Família; ****ONG Organização não governamental; *****SESI - Serviço Social da Indústria; ******SMS - Secretaria Municipal de Saúde. 
Esse envolvimento intersetorial traduz a atuação dos acadêmicos de enfermagem em redes, em consolidação à proposta da Política Nacional para a Promoção da Saúde (BRASIL, 2010), bem como o movimento empreendedor na busca de parcerias, compromisso e corresponsabilidade das ações de promoção e prevenção da saúde, junto aos diferentes atores envolvidos no processo de cuidado. Fortalecer as regiões para reduzir as desigualdades significa empoderar os atores sociais na busca de soluções e enfrentamento de seus problemas. Por sua vez, reconhecer a identidade cultural e a busca de novos conhecimentos e estruturas de uma região pode resultar em alternativas de desenvolvimento e melhoria da qualidade de vida de sua população (SEBASTIANY, 2012).

Cabe ressaltar a importância da inserção do acadêmico no mundo de trabalho em diferentes grupos sociais, uma vez que o atendimento integral à população em diferentes contextos sociais significa entender a heterogeneidade entre os usuários de saúde e suas singularidades sociais. Para Kuabara et al., (2014), a integração ensino-serviço possibilita a melhoria da qualidade do cuidado, uma vez que a mesma contribui para um olhar abrangente do indivíduo e as necessidades em saúde, além da melhoria das condições de vida. Dessa forma, faz-se importante a ampliação dos espaços de intervenção por meio da IES, em preocupação com o papel social que desempenham, uma vez que a vivência in loco da realidade da comunidade pode contribuir para uma formação profissional mais humanitária, baseada em cenários reais (MOIMAZ et al., 2010).

A utilização das intervenções comunitárias nos espaços sociais do território, nesse contexto, ganha destaque como potencialidades para a prática profissional. Entende-se que a realização dessas intervenções pode oferecer meios à comunidade para ajudá-la a conquistar autonomia e exercício da cidadania. Nessa perspectiva, dado a relevância para o futuro profissional, faz-se necessária a vivência dessas situações de intervenção em saúde que contemplem parcerias com outros setores durante a formação na graduação.

\section{Articulações intersetoriais e desenvolvimento regional em saúde}

Ao longo das duas últimas décadas (1990-2010), o Ministério da Saúde, por meio da APS, vem incentivando e implementando dispositivos que promovam a integralidade como diretriz orientadora de educação em saúde no SUS. Estabelece, entre suas características, a integralidade da assistência, a abordagem multiprofissional, o estímulo à ação intersetorial e à participação da comunidade (BRASIL, 2012). Assim, os profissionais de saúde, e em especial o enfermeiro, assumem responsabilidades para além de sua atuação clínica, atuando de modo interdisciplinar e multiprofissional, tendo como foco o fortalecimento das pessoas e da comunidade.

No panorama apresentado neste estudo, percebe-se que a estruturação das AIABs encontra, em seu cerne, um ambiente cultural favorável ao aprendizado. Por meio delas, os discentes têm a oportunidade de estabelecer uma rede de relações com a comunidade, que participa ativamente do planejamento e da execução das atividades, contribuindo com o seu processo educacional, e assumindo, portanto, contribuição ímpar no processo pedagógico de futuros enfermeiros e no processo de cuidado em enfermagem e saúde. 
Intervenções comunitárias em enfermagem: intersetorialidade, formação empreendedora e desenvolvimento regional em saúde

Nessa direção, a educação em saúde é apontada como estratégia essencial na promoção da saúde, para garantir informações e conhecimentos necessários à efetiva participação e ao empoderamento das pessoas e da comunidade (KLEBA et al., 2016). Essa perspectiva revela a intencionalidade dessas intervenções. Ao preocupar-se com as realidades com as quais se deparam em seus territórios, campos de estágio, os acadêmicos demonstram o desejo pela construção do desenvolvimento humano e social, algo que vai além da perspectiva clínica individual, e que explicita uma preocupação com as desigualdades sociais e com as necessidades de saúde da comunidade, da região, do país.

Para a efetivação da educação em saúde, a intersetorialidade apresenta uma grande contribuição, pois integra diferentes instituições e agentes com conhecimentos diversos sobre um mesmo território e sobre a população que o compõem, resultando em projetos adequados à identidade local. Segundo Dreher e Ullrich (2010), é por meio da constituição das organizações que o fortalecimento da sociedade civil se torna produto da capacidade das organizações de articularem esforços convergentes visando a benefícios comuns e ao bem-estar social.

Por meio das AIAB, os acadêmicos apoiam-se em fundamentos de cooperação, rede e democracia como elementos necessários ao desenvolvimento regional em saúde. Percebe-se que, no desenvolvimento destas intervenções, esses acadêmicos contam com a participação da comunidade para o alcance de suas metas e, assim, vislumbra-se um terreno fértil para as boas práticas de enfermagem na comunidade. Ao mesmo tempo, as AIAB contemplam a responsabilidade social universitária - RSU, pois, além das alianças realizadas para a operacionalização das atividades, o resultado das mesmas é um esforço mútuo e compartilhado para a busca de soluções, como defende Vallaeys (2016).

Entretanto, apesar da importante relação entre saúde e educação, compreendida e planificada pelo Programa Saúde na Escola (BRASIL, 2007), não observou-se a presença de instituições públicas de educação básica nos registros das ações promovidas nestas AIAB. Isso é um ponto a ser refletido e melhor analisado, haja vista o grande potencial da escola na promoção da saúde, por sua abrangência social e por ser um espaço propício a trocas, à socialização, e à construção do saber de modo ativo (NASCIMENTO; FERNANDES, 2008).

Possivelmente, a não participação das escolas da comunidade nas ações seja explicada, em parte, pelas inúmeras tarefas e conteúdos que sobrecarregam essas instituições, ou mesmo por incompletude nos registros destas atividades. Diante disso, reforça-se a importância dessa articulação ao reafirmar os dizeres de Meresman (2008), o qual propõe que a educação para a saúde seja praticada na escola não como um adorno, como algo a mais, mas que as práticas não saudáveis sejam banidas dela. Em análise às AIAB, percebe-se que as articulações tecidas para sua operacionalização, ensejam a oportunidade de abordar conteúdos cotidianos da saúde, e que envolvem a necessidade de boas práticas da enfermagem, com base no comprometimento dos diversos atores sociais da comunidade, despertando-os para a consciência social.

Dessa maneira, a articulação entre a universidade e as escolas da comunidade deve guardar em si que a saúde consiste em prática cotidiana, e não em mais um conteúdo escolar a ser ensinado e aprendido. Constitui-se, assim, a necessidade de maior articulação entre o ensino universitário e o ensino nas escolas 
da comunidade, como contexto propício à promoção da educação em saúde, na medida em que permite aos atores envolvidos neste contexto, transcender os seus muros, e propagar-se às comunidades locais. A articulação desse e de outros cenários de produção em saúde, por meio de seus atores sociais, pode ser fomentador de práticas que favorecem a transformação social, acarretando uma maior participação em ações coletivas e intersetoriais em saúde.

\section{Reconhecimento de oportunidades de intervir em saúde}

As intervenções comunitárias elencadas estão permeadas por diversos fatores da realidade social. Nas AIAB essas oportunidades se traduzem em novos modos de olhar para a comunidade, e emergem de necessidades de saúde não satisfeitas, bem como de problemas não resolvidos. Contudo, os documentos e registros a elas relacionadas mostram que estas não devem ser identificadas por aproximação dos alunos com a temática, mas, sim, a partir do profundo conhecimento do território e do ambiente em que pretende intervir.

Nesse sentido, a formação acadêmica em enfermagem proposta neste cenário instiga o desenvolvimento de saúde que considerem a importância de perceber as necessidades de saúde de indivíduos, grupos e comunidades, concebendo modos de satisfazê-las, e de gerenciar recursos para a criação e consolidação de ações que assegurem as boas práticas no processo de cuidado. Tais práticas ultrapassam o domínio dos conteúdos científicos, técnico-assistenciais da enfermagem e despertam nestes futuros enfermeiros a capacidade de empreender e, consequentemente, produzir mudanças que favoreçam o desenvolvimento regional em saúde para a coletividade.

Diante disso, surgem desafios para os profissionais da enfermagem, que devem atuar na comunidade e manter a qualidade das intervenções em contextos de grande complexidade, elencar práticas profissionais baseadas em evidências científicas e facilitar o acesso aos cuidados de saúde eficazes, a fim de garantir a promoção do empoderamento comunitário (SOUSA et al., 2017). Além disso, é necessário o desenvolvimento de habilidades específicas para enxergar o indivíduo de forma integral, levando em consideração a indissociabilidade dos determinantes sociais da saúde.

Os determinantes sociais da saúde vinculam-se aos comportamentos individuais e às condições de vida e trabalho, à macroestrutura econômica, social e cultural (WHO, 2008). Nesse sentido, são considerados dimensões tal como os fatores sociais, econômicos, culturais, étnico-raciais, psicológicos e comportamentais que influenciam a ocorrência de problemas de saúde e seus fatores de risco na população (ALBUQUERQUE; SILVA, 2014).

Debater e identificar tais determinantes junto à comunidade é importante, especialmente quando se relacionam os cuidados e direitos em saúde e direitos sociais, buscando assegurar que todos tenham oportunidade de acesso e de garantia de direitos sociais universais. No entanto, é necessário que os profissionais de saúde compreendam o processo de reestruturação produtiva, que tem acentuado as desigualdades sociais, em termos de classe e de região. Para isso, é essencial que as IESs busquem a formação de profissionais de saúde baseados no desenvolvimento de competências profissionais em dimensões que extrapolem o 
Intervenções comunitárias em enfermagem: intersetorialidade, formação empreendedora e desenvolvimento regional em saúde

âmbito técnico-científico, tornando-os instruídos para capacidade de compreensão política sobre a realidade de vida da população e, assim, potencializando a atuação dos profissionais de saúde para além do atendimento apenas aos sinais e sintomas dos adoecimentos (OLIVEIRA et al., 2011).

No contexto deste estudo, foram identificadas diversas ações empreendidas pelos acadêmicos em ECS, visando o alcance das metas e objetivos a que se propuseram em suas AIAB. No Quadro 2, apresentam-se as ações desenvolvidas nessas atividades, de modo sumarizado.

\section{Quadro 2. Descrição das ações desenvolvidas nas intervenções, Vale do Paranhana, RS, Brasil, 2018}

Número de pessoas atendidas: 1.017

\section{Ações desenvolvidas}

Aferição de $\mathrm{PA}^{* *}$, IMC* e $\mathrm{RCQ}^{* * *}$, com reflexão acerca destes parâmetros e entrega de caderneta com os registros

Apresentações artísticas culturais

Atividade físicas, de bem-estar e promotoras de qualidade de vida e saúde

Avaliação de acuidade visual, glicose capilar e medidas antropométricas

Atendimento ginecológico de enfermagem

Discussões em rodas de conversa e distribuição de folders educativos sobre saúde e adoecimento mental, riscos de suicídio, prevenção, mitos e verdades

Dinâmicas voltadas à saúde física, mental e alimentar

Distribuição de frutas, alimentos e bebidas patrocinados pela comunidade

Doações de livros e sorteio de brindes

Informações sobre autocuidado em saúde, com entrega de folders educativos e dicas de saúde

Espaço de beleza, autoestima e saúde

Espaço para fotografias, entretenimento e lazer

Espaço para produção, divulgação e comercialização de artesanato

Exposição de trabalhos concebidos no âmbito do CAPS**** e de outros serviços

Exposição do CRAS***** e divulgação do seu papel junto à sociedade

Jogos educativos, interativos e de entretenimento

Orientações focada em ações programáticas: saúde da mulher, saúde mental, do homem, da criança, dentre outras

Orientações de saúde bucal e distribuição de escovas e cremes dentais

Orientações para descarte de materiais contaminados e contribuições para o meio ambiente

Orientações sobre infecções sexualmente transmissíveis, realização de testes-rápidos de

HIV******, Sífilis e hepatites, e aconselhamento sobre prática sexual segura

Orientações preventivas sobre o câncer de mama, de colo de útero e de próstata

Orientações sobre planejamento familiar, gestação e violência à mulher

Orientações sobre tabagismo, álcool e outras drogas

Orientações sobre diversidade e cidadania

Práticas recreativas e lúdicas com crianças

Terapias complementares: quiropraxia, shiatsu

Fonte: Quadro elaborado pelos autores, 2018. *IMC - Índice de Massa Corporal; *PA - Pressão Arterial; ***RCQ - Relação Cintura Quadril; ****CAPS - Centro de Atendimento Psicossocial; *****CRAS Centro de Referência de Assistência Social; *****Vírus da Imunodeficiência Humana. 
Entende-se que a diversidade de ações desenvolvidas nas AIAB tem potencial de contribuir para o exercício da cidadania dos atores envolvidos, levando em consideração a pluralidade de orientações e atividades desenvolvidas nas ocasiões em que ocorreram, bem como os diferentes papéis desempenhados pelos mesmos, que transitam da posição de educador e educando, entrelaçando saberes e informações. Nesse processo, o conhecimento dos sujeitos é dinâmico, influenciável e influenciador, construindo e desconstruindo ideias e saberes sobre dado assunto (VALE; PAGLIUCA; QUIRINO, 2009).

Propelir movimentos que desencadeiem reflexões sobre o processo de saúde e doença, ao mesmo tempo em que oferecem um ambiente dinâmico e atrativo, faz com que os atores envolvidos contribuam e tenham contribuição para sua saúde e, consequentemente, para que atuem para o desenvolvimento social e econômico da região em que estão inseridos. Nesse sentido, corroboramos da assertiva de Freire (2002), quando defende que aprender não se limita a tornar o indivíduo adaptado à realidade, mas contribuir para torná-lo ativo, capaz de transformá-la e intervir sobre ela, recriando-a.

A partir do exposto, são apresentados os movimentos empreendedores das atividades aqui trazidas, a partir da formação em saúde.

\section{Movimentos empreendedores na formação em saúde}

Os modelos assistenciais em saúde refletem a importância das políticas de saúde em articulação com diversos setores da sociedade no intuito de conferir resolubilidade às práticas de saúde comunitárias, o que demanda olhar aprofundado para as influências históricas, culturais, políticas e aspectos demográficos e sanitários. A transformação social avança para uma crescente diversidade cultural na perspectiva de ajustes na atenção ao cuidado em saúde, tanto na pesquisa quanto no ensino ou no serviço, combinando conhecimentos e ações sociais diversas, frente às necessidades de prestação de cuidados de saúde de alta qualidade (RODRIGUES; PEREIRA; AMENDOEIRA, 2015).

A proposta das AIAB demonstra alinhamento a esta perspectiva, na medida em que promove movimentos empreendedores que incitam em seus acadêmicos a atuação como agentes de mudanças. A partir destas, os acadêmicos assumem a tarefa de gerar valores para a comunidade, exercitando a capacidade de inovar e de buscar sustentabilidade para as práticas que desenvolvem.

Nessa perspectiva, o modelo tradicional de formação em saúde, alicerçado em uma visão mecanicista e reducionista, perde a multidimensionalidade. As críticas a esse modelo estão cada vez mais presentes com as novas descobertas e experiências científicas, práticas e tecnológicas (RODRIGUES; PEREIRA; AMENDOEIRA, 2015), aguçando movimentos que enfocam o processo de cuidado fundamentado nas boas práticas de enfermagem, pautadas em princípios doutrinários do SUS, em atenção aos indivíduos, grupos e comunidades, e ponderando os determinantes que incidem sobre suas relações sociais, políticas, econômicas e culturais.

Nesse cenário, a transição de um modelo técnico e positivista para um modelo de competências do cuidar reflete na enfermagem como uma perspectiva para o seu desenvolvimento e progresso como disciplina, a partir de uma visão 
Intervenções comunitárias em enfermagem: intersetorialidade, formação empreendedora e desenvolvimento regional em saúde

multiparadigmática nas intervenções (MELEIS, 2011). Essa perspectiva reforça a proposição de iniciativas semelhantes à proposta das $A I A B$, uma vez que corrobora a concepção de que a universidade não é o único lugar para aprender. Ao se propor a intervenção em uma realidade local, os acadêmicos receberão orientações sobre a criação de tecnologias disruptivas, estímulo à busca e criação de oportunidades e diretrizes fundamentais ao fortalecimento da rede de relações e à prática de gerenciamento de recursos e processos.

Para Amendoeira (2010), essa transição de pensamento gera uma nova demanda para o cuidado em saúde, havendo a necessidade da reformulação das políticas públicas, além do desenvolvimento de atitudes para o reconhecimento de saberes sob a ótica da inter e transdisciplinaridade. Diante disso, faz-se necessário o reconhecimento dos limites de suas práxis de atuação e das tecnologias empregadas numa relação de parceria entre os demais saberes e setores da sociedade.

Nesse sentido, Vieira et al. (2016) apontam que a formação do enfermeiro deve primar por capacitá-lo a identificar seu escopo de atuação e planejar ações conjuntas, enfrentar os desafios na formação crítica, reflexiva e interdisciplinar. $\mathrm{Na}$ perspectiva das $\mathrm{AIAB}$, os estudantes, inseridos em um contexto histórico e contemporâneo, são impelidos a propor ações que impactem na melhoria do estado de saúde da população do entorno em que os serviços de saúde estão inseridos, a partir de iniciativas empreendedoras, que considerem a transformação das condições de saúde daquelas. A proposta é que os estudantes desenvolvam competências necessárias ao agir crítico e reflexivo, baseado em evidências e nos indicadores reconhecidos no cenário, para atuarem como agentes de mudança no contexto social.

\section{CONSIDERAÇÕES FINAIS}

A mobilização de diversos atores e setores pode constituir um desafio, haja vista os diferentes entendimentos trazidos pelos sujeitos envolvidos. Entretanto, a proposição de ações que viabilizem o trabalho em saúde na perspectiva da intersetorialidade, são de grande importância para o desenvolvimento de determinada região. Essas ações mobilizam os diferentes conhecimentos sobre uma mesma realidade, permitindo a cooperação, o senso de pertencimento e de coletividade.

Nesse sentido, o foco das intervenções em saúde e em enfermagem mudam constantemente, ficando o desafio para o ensino na saúde voltar-se para o desenvolvimento da capacidade de compreender o que se passa no ambiente, e de produzir conhecimentos que possam conferir valor aos outros. Assim, nos processos de ensino e aprendizagem em enfermagem, a participação de diversos atores que têm interface com a saúde mostra-se essencial, pois coloca o profissional da saúde mais próximo do usuário e da sua realidade, permitindo identificar, de modo mais efetivo, demandas e necessidades de saúde que se sobrepõem, elaborando novas e diferentes maneiras de intervir.

Aos acadêmicos, esse contato com a população é extremamente pertinente e a mobilização de ações que envolvam diversos atores permite uma experiência que enriquece sua capacidade crítica, sua capacidade de observar e interpretar as 
diferenças territoriais e interpretar as diferentes informações trazidas pelos atores envolvidos. Ações organizadas por acadêmicos enriquecem a formação profissional destes e aproximam a academia da sociedade, o que permite às IESs maior inserção na comunidade que a cerca, resultando em uma educação superior vinculada à realidade social, política e econômica da região.

Percebe-se que o maior desafio à intersetorialidade nas ações em educação para a saúde é a participação de instituições públicas de educação básica. Apesar da existência de um programa governamental para a saúde na escola, quando existe alguma ação na própria instituição, ela recebe a conotação de adorno, como algo que foi imposto e, portanto, pouco significativo. A partir do reconhecimento do potencial da escola no que tange à inserção na comunidade e à formação de cidadãos, aponta-se para a necessidade da busca destas instituições para partilharem das AIAB, dotando de maior significado os encontros estabelecidos durante estas atividades, bem como a vinculação inexorável das famílias e, portanto, maior alcance das ações empreendidas.

\section{REFERÊNCIAS}

ALBUQUERQUE, Guilherme Souza Cavalcanti de; SILVA, Marcelo José de Souza. Sobre a saúde, os determinantes da saúde e a determinação social da saúde. Saúde em Debate, v. 38, p. 953-965, 2014. Disponível em: <https://www.scielosp.org/article/sdeb/2014.v38n103/953-965/> Acesso em 29 mai. 2018.

AMENDOEIRA, José. Políticas de saúde em Portugal e desigualdades. 2 ed. Santarém: Portugal, 2010. Disponível em: <http://repositorio.ipsantarem.pt/bitstream/10400.15/86/1/Pol\%C3\%ADticas\%20de\%20 sa\%C3\%BAde\%20em\%20Portugal\%20e\%20desigualdades.pdf> Acesso em: 29 mai. 2018.

BASSAN, Dilani Silveira. Mobilidade espacial: a dinâmica das migrações e a trajetória dos migrantes na região do Vale do Paranhana/RS-Brasil. 2017. Disponível em: <https://repositorio.unisc.br/jspui/bitstream/11624/1509/1/Dilani\%20Silveira\%20Bassan .pdf> Acesso em: 22 jun. 2018.

BRANDÃO, Edermeson R. Malheiro; ROCHA, Saulo Vasconcelos; SILVA, Sylvia Sardinha da. Práticas de Integração Ensino-Serviço-Comunidade: Reorientando a formação médica. Rev. Bras. de Educação Médica, v. 37, n. 4, p. 573-577. Disponível em <http://www.scielo.br/pdf/rbem/v37n4/a13v37n4.pdf>. Acesso em 31 mai. 2018.

BRASIL. Ministério da Saúde. Datasus. 2018. Disponível em:

<http://tabnet.datasus.gov.br/cgi/tabcgi.exe?cnes/cnv/estabrs.def> Acesso em: 22 jun. 2018.

BRASIL. Constituição (1988). Constituição da República Federativa do Brasil.

Brasília, DF: Senado Federal.1988. Disponível em: 
Intervenções comunitárias em enfermagem: intersetorialidade, formação empreendedora e desenvolvimento regional em saúde

<http://www.planalto.gov.br/ccivil_03/constituicao/constituicaocompilado.htm.> Acesso em: 30/05/2018.

BRASIL. Decreto $n^{\circ} 6.286,5$ de dezembro de 2007. Institui o Programa Saúde nas Escolas. Brasília, DF, 2007. Disponível em: http://www.planalto.gov.br/ccivil_03/_at02007-2010/2007/decreto/d6286.htm. Acesso em: 30/05/2018.

BRASIL. Ministério da Saúde. Secretaria de Vigilância em Saúde. Secretaria de Atenção à Saúde. Política Nacional de Pem:

<http://bvsms.saude.gov.br/bvs/publicacoes/politica_nacional_promocao_saude_3e d.pdf> Acesso em: 30/05/2018.

CALDAS, José Manuel Peixoto; SANTOS, Zélia Maria de Sousa Araújo. Saúde e equidade. Revista da Escola de Enfermagem da USP, v. 50, n. 4, p. 540-541, 2016. Disponível em: <http://www.redalyc.org/pdf/3610/361047445001.pdf> Acesso em: 31 mai. 2018.

DREHER, Marialva Tomio; ULLRICH, Danielle Regina. Confiança interparceiros e disposição para cooperar em ações de responsabilidade social no desenvolvimento local. REDES, Santa Cruz do Sul, v. 15, n. 2, p. 172 - 190, maio/ago. 2010 Disponível em:<https://online.unisc.br/seer/index.php/redes/article/view/1112/1475> Acesso em: 30 mai. 2018.

FACCAT. Faculdades Integradas de Taquara. Projeto Pedagógico Institucional (PPI) 2015-2020. Revisado 2017. Taquara, 2017.

FISCHBORN, Aline Fernanda. Saúde e desenvolvimento: uma análise a partir do conceito de desenvolvimento de Amartya Sen. Desenvolvimento Regional em debate: DRd, v. 5, n. 1, p. 201-210, 2015. Disponível em: <https://dialnet.unirioja.es/servlet/articulo?codigo=5443973> Acesso em: 30 mai. 2018

FREIRE, Paulo. Pedagogia da autonomia: saberes necessários à prática educativa. Rio de Janeiro: Paz e Terra; 2002.

FUNDAÇÃO DE ECONOMIA E ESTATÍSTICA - FEE. Resumo Estatístico Municipal. Disponível em: <https://www.fee.rs.gov.br/> Acesso em: 22 jun. 2018.

GADELHA, Carlos Augusto Grabois; COSTA, Laís Silveira. Saúde e desenvolvimento no Brasil: avanços e desafios. Revista de Saúde Pública, v. 46, n. spe, p. 13-20, 2012. Disponível em: <https://www.scielosp.org/article/ssm/content/raw/?resource_ssm_path=/media/ass ets/rsp/v46s1/co4193.pdf> Acesso em: 28 mai. 2018.

KLEBA, Maria Elisabeth et al. Trilha interpretativa como estratégia de educação em saúde: potencial para o trabalho multiprofissional e intersetorial. Interface- 
Comunicação, Saúde, Educação, v. 20, p. 217-226, 2015. Disponível em: $<$ https://www.scielosp.org/scielo.php?pid=S1414-

32832016000100217\&script=sci_abstract\&tlng=es> Acesso em: 30 mai. 2018.

KUABARA, Cristina Toschie de Macedo et al. Integração ensino e serviços de saúde: uma revisão integrativa da literatura. Revista Mineira de Enfermagem, v. 18, n. 1, p. 195-207, 2014. Disponível em: <http://www.dx.doi.org/10.5935/1415-2762.20140015> Acesso em: 30 mai. 2018.

MELEIS, AFAF I. Transitions theory. Nursing theories and nursing practice, p. 361$380,2015$.

MERESMAN, Sérgio. $O$ que a escola tem a ver com a saúde comunitária?. In.: Boletim Saúde e Educação, v. XVIII, n. 12. 2008. p. 38 - 42. Disponível em: <http://www.cedaps.org.br/wp-content/uploads/2013/07/Boletim-Saude-eEducacao.pdf.> Acesso em: 30/05/2018.

MOIMAZ, Suzely Adas Saliba et al. Práticas de ensino-aprendizagem com base em cenários reais. Interface-Comunicação, Saúde, Educação, v. 14, p. 69-79, 2010. Disponível em: <https://www.scielosp.org/article/icse/2010.v14n32/69-79/pt/> Acesso em: 31 mai. 2018.

NASCIMENTO, Geisa; FERNANDES, Cecília. Saúde é matéria de escola?. In.: Boletim Saúde e Educação, v. XVIII, n. 12. 2008. p. 32 - 37. Disponível em: <http://www.cedaps.org.br/wp-content/uploads/2013/07/Boletim-Saude-eEducacao.pdf.> Acesso em: 30/05/2018.

OLIVEIRA, Gilson Batista; LIMA, José Edmilson de Souza. Elementos endógenos do desenvolvimento regional: considerações sobre o papel da sociedade local no processo de desenvolvimento sustentável. Revista da FAE, v. 6, n. 2, 2003. Disponível em: <https://revistafae.fae.edu/revistafae/article/view/462/357> Acesso em: 30 mai. 2018.

OLIVEIRA, Giordano Pedro et al. Os desafios para a intervenção em saúde na estratégia de saúde da família segundo os profissionais. Cogitare Enfermagem, v. 16, n. 3, 2011. Disponível em: <http://www.redalyc.org/html/4836/483648968008/> Acesso em: 30 mai. 2018.

PINHEIRO, Ricardo Lana; GUANAES, Carla. O conceito de rede social em saúde: pensando possibilidades para a prática na estratégia saúde da família. Nova Perspectiva Sistêmica, v. 20, n. 40, p. 9-25, 2016. Disponível em: <http://revistanps.com.br/index.php/nps/article/view/8o/192> Acesso em: 28 mai. 2018.

PIZZINATO, Adolfo et al. A integração Ensino-Serviço como estratégia na formação profissional para o SUS. Revista Brasileira de Educação Médica, v. 36, n. 1, Supl. 2, p. 
Intervenções comunitárias em enfermagem: intersetorialidade, formação empreendedora e desenvolvimento regional em saúde

170-177. Disponível em <http://www.scielo.br/pdf/rbem/v36n1s2/a25v36n1s2.pdf>. Acesso em 31 mai. 2018.

POUPART, Jean et al. A pesquisa qualitativa: enfoques epistemológicos e metodológicos. In: A pesquisa qualitativa: enfoques epistemológicos e metodológicos. 2014.

QUEZADA, Ricardo Gaete. La responsabilidad social universitaria como desafío para la gestión estratégica de la Educación Superior: el caso de España The university social responsibility as a challenge to the strategic management of Higher Education: the case of Spain. Revista de educación, v. 355, p. 109-133, 2011. Disponível em: <http://www.revistaeducacion.educacion.es/re355/re355_05.pdf> Acesso em: 30 mai. 2018.

RIO GRANDE DO SUL. Perfil Socioeconômico COREDE Paranhana Encosta da Serra, 2015. Disponível em: <

http://planejamento.rs.gov.br/upload/arquivos/201512/15134135-20151117103226perfisregionais-2015-paranhana-encosta-da-serra.pdf> Acesso em: 22 jun. 2018.

RODRIGUES, Francisco Rafael; PEREIRA, Maria Lúcia Duarte; AMENDOEIRA, José. A transição paradigmática da saúde e suas reflexões na enfermagem como disciplina.

Revista Rede de Cuidados em Saúde, v. 9, n. 1, 2015. Disponível em: <http://publicacoes.unigranrio.com.br/index.php/rcs/article/view/2516/1281> Acesso em: 31 mai. 2018.

SEBASTIANY, Giana Diesel. As diferentes possibilidades de regionalização de um território: delimitações a partir da categoria saúde. Desenvolvimento Regional em debate: DRd, v. 2, n. 2, p. 139-160, 2012. Disponível em:

<https://dialnet.unirioja.es/servlet/articulo?codigo=5443912> Acesso em: 30 mai. 2018.

SOUSA, Fábio Alexandre Melo et al. Estabelecimento de prioridades em saúde numa comunidade: análise de um percurso. Revista de Saúde Pública, v. 51, p. 1-10, 2017. Disponível em: <http://www.redalyc.org/pdf/672/67249591010.pdf> Acesso em: 30 mai. 2018.

VALLAEYS, François. Responsabilidad e instituciones responsables en un mundo globalizado. Cuadernos de Ética y Filosofía Política. Ano 5, n. 5, p. 86-93. Disponível em

<https://www.academia.edu/31647773/Responsabilidad_e instituciones_responsabl es_en_un_mundo_globalizado> Acesso em 31, mai. 2018.

VALE, Eucléa Gomes; PAGLIUCA, Lorita Marlena Freitag; QUIRINO, Régio Hermilton Ribeiro. Saberes e práxis em enfermagem. Esc. Anna Nery, Rio de Janeiro, v. 13, n. 1, p. 174-180, Mar. 2009. Disponível em <http://www.scielo.br/scielo.php?script=sci_arttext\&pid=S1414-

$81452009000100024 \&$ lng=en\&nrm=iso >. Acesso em 31 Mai 2018. 
VIEIRA, Maria Aparecida et al. Diretrizes curriculares nacionais para a área da enfermagem: o papel das competências na formação do enfermeiro. Renome, v. 5, n. 1, p. 105-121, 2016. Disponível em:

<http://www.renome.unimontes.br/index.php/renome/article/view/102/148> Acesso em: 31 mai. 2018.

WHO - World Health Organization; Comissão Nacional Sobre os Determinantes Sociais da Saúde. As causas sociais das iniqüidades em saúde no Brasil. 2008. Disponível em: <www.determinantes.fiocruz.br>. Acesso em: 29 ago. 2013.

Gímerson Erick Ferreira. Enfermeiro. Doutor em Enfermagem pela Universidade Federal do Rio Grande do Sul (UFRGS), Escola de Enfermagem (EE), Programa de Pós-Graduação em Enfermagem (PPGENF). Professor Adjunto na Faculdade de Enfermagem (FAEN) da Universidade Federal do Mato Grosso (UFMT). Cuiabá, MT, Brasil.gimeferreira@gmail.com

Edemilson Pichek dos Santos. Enfermeiro. Mestrando em Desenvolvimento Regional pelo Programa de Pós-Graduação das Faculdades Integradas de Taquara (PPGDR-FACCAT). Bolsista CAPES. Taquara, RS, Brasil. edemilson@sou.faccat.br

Amanda Silveira Duarte Gomes. Licenciada em Letras pela Faculdade Cenecista de Osório (FACOS). Mestrando em Desenvolvimento Regional pelo Programa de Pós-Graduação das Faculdades Integradas de Taquara (PPGDR-FACCAT). Bolsista CAPES.Torres, RS, Brasil. amandasduartegomes@gmail.com

Claudia Capellari. Enfermeira. Doutoranda em Medicina e Ciências da Saúde pelo Programa de Pós-Graduação da Pontifícia Universidade Católica do Rio Grande do Sul (PUC-RS). Mestre em Enfermagem pela Universidade Federal do Rio Grande do Sul (UFRGS). Coordenadora e Professora da Graduação em Enfermagem (FACCAT). Taquara, RS, Brasil. claudiacapellari@faccat.br

Roberto Tadeu Ramos Morais. Doutor em Desenvolvimento Regional pela Universidade de Santa Cruz do Sul (UNISC). Professor do Programa de PósGraduação em Desenvolvimento Regional das Faculdades Integradas de Taquara (PPGDR-FACCAT), Vice-Diretor de Pesquisa e Pós-Graduação. Taquara, RS, Brasil. masprm@faccat.br 